\title{
Develop Ryden Self-Esteem Test on Jordanian Universities Students and Its Relationship with Bar-On Emotional Intelligence Test
}

\author{
Hiba Hammad ${ }^{1, *}$ \\ ${ }^{1}$ Princess Alia University College, Al Balqa Applied University, Amman, Jordan \\ *Corresponding author: Princess Alia University College, Al Balqa Applied University, \\ Amman, Jordan
}

Received: February 26, 2017 Accepted: March 13, 2017 Published: March 27, 2017

doi:10.5296/ije.v9i1.10996 URL: https://doi.org/10.5296/ije.v9i1.10996

\begin{abstract}
The purpose of this study is to Develop Ryden self-esteem test on Jordanian universities students and to investigate its relationship with Bar-On emotional intelligence test; it also aims to investigate the effect of gender on self-esteem. The research problem was represented in the following main question: what is the relationship between emotional intelligence and self-esteem. The researcher raised four questions in this research.

The sample of this research was consisted of (219) male \& female students from both colleges of Princess Alia and Amman University College/ Al Balqa Applied University. Two scales were used in this research including a scale of emotional intelligence, and a scale of self-esteem. Researcher used statistical methods as following: $\mathrm{T}$ test, the relative weight (percentage) and multiple regression analysis, the research outcome revealed that there is a significant statistical difference between males and females in emotional intelligence in favor of males. Results also showed that there is a significant statistical impact of the emotional intelligence on Self-esteem.
\end{abstract}

Keywords: emotional intelligence, self-esteem, Ryden self-esteem, Bar-On emotional intelligence test 


\section{Introduction}

The concept of emotional intelligence had found a paramount importance in the last two decades, it has addressed many of educational studies, psychological and social research. The book which published by Mayer \& Salovey in 1990 entitled imagination, knowledge and personal is considered the first actual attempts to Interest this concept, and Daniel Goleman in 1995 has issued his famous book "Emotional Intelligence," which contributed to the elaboration of this concept and its spread.

The concept of emotional intelligence has attracted the attention of many of the world's communities when they passed in cultural, racial problems, (Pfeiffer, 2001) at the end of the twentieth century. As a result; it has been shown in some of books and on the network to find out how researchers deal with him? And how to link it to some variables (Abi Samka, 2000)

Emotional intelligence means the ability to understand, evaluate and manage our emotions and the emotions of others, it represents with intelligence quotient (I Q) integrated form of the our intelligence, while people need a lot of IQ in order to behave in a good way, the emotional intelligence that distinguishes the prominent leaders. (Bourey \& Miller, 2001)

Emotional intelligence consists from personal intelligence and interpersonal intelligence (Social Intelligence), as for personal intelligence makes us feel the internal relations between our thoughts and events that face us, and the social Intelligence make us deal with others and communicate with them easily (Foote, 2001)

Emotional intelligence and its relationship to some emotional variables among university students

Mayer \& Salovey (1997) defined Emotional Intelligence as: an individual's ability to perceive emotions to reach the generalization that emotion to help him think, understand and know the emotions of others that lead to the organization and development of mental development relating to that feeling. (Mayer \& Salovey,1997).

Goleman mentioned that the individual has tow minds: the emotional mind and the logical mind with a gorgeous coordination between others, whereas feelings and emotions necessary to think, and thinking necessary for feelings and emotions (Maghazi, 2003), then the emotional situation affects the private mental status of teachers, and students with high degrees of anxiety, anger, depression, do not learn efficiently, so the one who becomes prey to such cases can not absorb the information efficiently, and can not take advantage of them, so when emotions attack the focus they disrupted mental capacity, particularly working memory, which is the ability to recall information that are related to the task faced by the individual (Robbins \& Scott, 2000).

\section{Self-esteem}

Cohen defined (Cohen, 1959) that self-esteem is the degree of congruence between the (ideal self) and (self-realism) while Argyle (1967) seen as: as a personal appreciation of the spacing between these two concepts. 
Cooper Smith also defined (Smith, 1967) self-esteem: As a assess puts by individual for himself by himself and works to maintain it. Self-esteem includes positive and negative individual trends toward himself, also it illustrates the extent of the individual's belief that is capable, significant and successful and efficient, i.e. that self-esteem is Individual judgment on the degree of efficiency of personal, also expresses individual attitudes toward himself or his beliefs about her. Thus, the self-esteem as a subjective experience of the individual transmitted to others by using various expressive methods. The previous definition requires clarifying the following:-

1- The self-esteem possess a degree of stability and permanence.

2- If the individual assessment towards himself varies from situation to situation of the area to another and from one role to another, but the self-esteem includes an individual assessment of the overall assessment of his abilities, it stems from a sense of individual self-importance of those positions and areas and roles.

3- The term self-evaluate is used to refer to the judgment of individual on the degree of its efficiency and its worth, the term self-evaluate is used to refer to the judgment of the individual on the degree of its efficiency and its worth, this assessment based on what individual passed through positions tested the capacity and performance, Then issue his judgments on those capabilities and on that performance; based on what he has of standards and values.

\subsection{Statement of the Problem}

Emotional intelligence has a capability could be expressed through a range of skills enhance the individual to formulate his objectives for long-term in light of the appreciation of the current potential and realizes himself differently in a way facilitate his self-esteem and achieve and make the effort to face failure and makes his appreciation and his judgment on the internal things that comes from him personally and give him the emotional experiences that make him avoids shame in situations that do not require interaction with any kind of shyness.

The areas of emotional intelligence still need more study of some of the other variables that current research is trying to be disclosed and its related and private self-esteem and a researcher that self-esteem is believed a prominent role in defining the concept of emotional intelligence. the problem of current research interested in the detection of self-esteem in light of emotional intelligence variable among Jordanian university students and the current research is trying to answer the following main question- :

What is the relationship between emotional intelligence and self esteem?

\subsection{Purpose of the Study}

The purpose of this study is to Develop Ryden self-esteem test on Jordanian universities students and to investigate its relationship with Bar-On emotional intelligence test; it also aims to investigate the effect of gender on self-esteem. 


\subsection{Questions of the Study}

The study seeks to answer the following questions:

1. What is the level of emotional intelligence scores among Jordanian university students?

2. What is the level of self-esteem scores among Jordanian university students?

3. Are there any statistically significant differences in emotional intelligence attributed to gender variable?

4. Is there a statistically significant effect of emotional intelligence on the self-esteem of students in Jordanian universities?

\subsection{Definition of Terms}

\subsubsection{Emotional intelligence:}

Emotional intelligence (EI) refers to the ability to perceive, control and evaluate emotions. Some researchers suggest that emotional intelligence can be learned and strengthened, while others claim it is an inborn characteristic.

\subsubsection{Self-esteem:}

Self-esteem is how we value ourselves; it is how we perceive our value to the world and how valuable we think we are to others. Self-esteem affects our trust in others, our relationships, our work nearly every part of our lives. Positive self-esteem gives us the strength and flexibility to take charge of our lives and grow from our mistakes without the fear of rejection.

\section{Literature Review}

Many researchers tackled the issue of emotional intelligence and its relationship with some variables such as self-esteem; some of these studies were reviewed as follows:

Musa and Hattab (2003) conducted a study aimed to detecting differences in some psychological variables (innovative characteristics, and self-esteem, and shame among individuals, high and low emotional intelligence of both sexes, results of the study have resulted in the presence of a statistically significant effect at level (0.01) to the variable of emotional intelligence (high, low) in the innovative characteristics. The results also showed a trace of the sex variable in the innovative characteristics, and results indicated that males are characterized by innovative characteristics Higher than females.

Sorour (2003) conducted a study aimed to recognize the face of pressure contrast and contrast the level of emotional intelligence (high, low) the total study sample has reached (526) students.

The results showed statistically significant differences between students with different levels 
of emotional intelligence in the face of pressure skills, it turns out that the significance of differences in favor of students with a high level of emotional intelligence. As it turns out the existence of a bilateral interaction with a statistically significant effect of emotional intelligence levels and gender on the face of pressures skills, as it turns out the lack of an interactive effect of demonstrating statistically between the level of emotional intelligence and control center and the kind of confrontation skills.

Furnham (2003) study aimed to recognize the correlation between emotional intelligence and happiness; the study sample consisted of 11 male and 77 female students the study has yielded the following results: The existence of a negative correlation between neurosis and happiness, The results showed there was no correlation between Cognitive ability and all the happiness and emotional intelligence, while the results showed a positive correlation between extroversion and happiness, as well as a relationship between emotional intelligence and happiness.

Roberts et al (2002) conducted a study aimed to study the global structure of the scale multi-factor emotional intelligence and emotional intelligence relationship with the major personal characteristics and the impact on the gender of emotional intelligence, the study sample consisted of 7-4 persons of men, women and applied to the sample list of five personality traits (neuroticism, extraversion, accepted, conscience vigilance, and openness to experience) And professional battery standby to measure IQ also the study showed several conclusions, including presence a positive relationship between the emotional intelligence and general intelligence and some personal variables (extraversion, admissibility, Conscience vigilance, openness to experience). While there is a negative correlation indicates a neuroticism trait, also there are differences between the Men and women in emotional intelligence in favor of women when they are estimating emotional intelligence and self-recognition In favor of men when the emotional intelligence estimate by experts.

Lindely (2001)conducted a study aimed to examine the relationship between emotional intelligence and some personal variables (extraversion, adjustment) the study sample consisted of 316 male and female students (105 male students ,211 female students) from the university students and general education and its applied Goleman list for emotional competencies (ECI), and some personal standards, also The study has showed a correlation coefficients by the presence of a function is positive relationship between emotional intelligence and some personal variables (diastolic) self-efficient, self-esteem, Optimism, internal locus of control and adjustment), while there is a negative correlation with the neuroticism trait, the study also showed that there are no significant differences between male and female students in emotional intelligence.

Lamanna (2000) conducted a study aimed to examine the relationship between emotional intelligence and between the point of control and depression among group of women (100 women), their ages ranged from 18-78 years and The study has been used list (Brown) to measure emotional intelligence and a disciple and a list of depression, and the study showed a correlation coefficients by the existence of a positive relationship between emotional intelligence and interior locus of Control, while there is a negative relationship between 
emotional intelligence with the external locus of control And depression.

Murensh (2000) conducted a study aimed to study the emotional intelligence and its relationship to the personal characteristics of the five major study has shown by correlation coefficients between the scores of monasteries (90 managers) on the list of Goleman efficiency affective (ECI) And their scores on the Personal List (NEO-PI) and a negative correlation between emotional intelligence and neuroticism trait while and found a positive relationship with the attributes of extraversion, openness to experience, and admissibility, vigilant conscience.

Coleman (1997) in his study aimed to reveal the role of campsites in the development of self-esteem and emotional intelligence, the study showed the importance of the role of campsites in the development of self-esteem and emotional intelligence among the camps pioneers, by development of physical security. Emotional safety building, creating a sense of identity, and develop a sense of belonging, and enhance efficiency and achieve a sense of mission. In addition to this study it found that it can achieve this goal through parental cooperation with the existing Committee on Training.

\section{Design and Methodology}

\subsection{Population of the Study}

All male and female students at Princess Alia University College and Amman University College enrolled in the educational specializations in the academic year 2015-2016.

\subsection{Sample of the Study}

The researcher used a sample of (219) students at Princess Alia University College / Al Balqa Applied University, and Amman University College, the respondents' ages for both males and females were between 19-22 years old and the arithmetic mean reached 21 years of age

\subsection{Instruments of the Study}

The researcher used the following tools to measure the variables of the study in the following order:

\subsubsection{Self-esteem scale:}

The scale of self-esteem which was used in the study was prepared by Ryden, and it consists of thirty items to measure three major dimensions that Ryden assume it represents the areas of self-esteem for Adults which are: Family self-esteem, school self-esteem, and the Peer self-esteem (group Friends). So the total number of scale items has become in its modified version on the Jordanian environment 30 items. The following table shows the distribution of the scale phrases on the three- Dimensions. 


\section{Macrothink}

Table 1. Distribution of the scale items on the three-Dimensions

\begin{tabular}{lll}
\hline Family self-esteem & school self-esteem & Peer self-esteem \\
\hline 1 & 11 & 21 \\
2 & 12 & 22 \\
3 & 13 & 23 \\
4 & 14 & 24 \\
5 & 15 & 25 \\
6 & 16 & 26 \\
7 & 17 & 27 \\
8 & 18 & 28 \\
9 & 19 & 29 \\
10 & 20 & 30 \\
\hline
\end{tabular}

The preparation and translation of the scale into Arabic language to make sure of its validity and reliability has passed into two stages until it became valid for use.

The first stage: It was translated of the scale from English to Arabic and from Arabic to English to ensure fidelity of translation. And to make sure the Arabic items does indeed transfer the intended meaning? Therefore, it was made several amendments, this was followed by writing the scale in its final form and they chose to answer either like me or not like me.

\subsubsection{Concurrent validity}

To measure the scale validity in its original image, the scale founder work to find a correlation coefficient, Cooper Smith questionnaire for self-esteem and the Rosenberg scale and its value was 0.83 , which indicates the existence of an agreement and harmony on the one hand between the validity of the three scales.

\subsubsection{Experts validity}

To measure the validity of the scale in the Jordanian environment, the researcher distributed the study tool in its initial version on a number of experts with experience and specialization in the field of education and psychology among faculty members at Al Balqa Applied University/ Princess Alia University College in Amman. The experts have expressed their views on the clarity of the questionnaire items and the relevance and appropriateness of bilateral gradient which determines the members of the study in response to each item in the questionnaire.

The researcher made adjustments by referring to reviewers comments where some items were modified and others were omit from the study tool. The number of items in the questionnaire in its final version was 30 items distributed as follows:

1- The first dimension describes a family self-esteem (10 first items of the questionnaire). 


\section{Macrothink}

2- The second dimension describes the school self-esteem (10 following items of the questionnaire).

3- The third dimension describes the Peer self-esteem (friends) (10 recent items of the questionnaire)

\subsubsection{Internal Consistency}

After ensuring of the arbitrators validity for the study tool, the researcher measure the validity of internal consistency, by Using the Pearson correlation coefficient to measure the relationship between the degree of the item and the total score of the dimension belonging to it and tables No. (2, 3 and 4) clarify this correlation.

It's clear from Table (2) that all correlation coefficients were obtained between the degree of each item in the family self-esteem dimension and the total score for that dimension is statistically significant at the level of (0.01) which shows the consistency of this dimension and the coherence of its provisions.

Table 2. The values of the correlation coefficient between each item and the total score of the family self-esteem dimension

\begin{tabular}{ll}
\hline Item No. & correlation coefficient \\
\hline 1 & 0.48 \\
2 & 0.38 \\
3 & 0.42 \\
4 & 0.29 \\
5 & 0.39 \\
6 & 0.52 \\
7 & 0.53 \\
8 & 0.45 \\
9 & 0.53 \\
10 & 0.39 \\
\hline
\end{tabular}

Evident from table No (3) that all correlation coefficients were obtained from the degree of each item of the Peer self-esteem dimension and total score for that dimension statistically significant at the level of (0.01). 


\section{Macrothink}

Table 3. The values of the correlation coefficient between each item and the total score of the Peer self-esteem dimension

\begin{tabular}{ll}
\hline Item No. & correlation coefficient \\
\hline 21 & 0.27 \\
22 & 0.37 \\
23 & 0.29 \\
24 & 0.21 \\
25 & 0.35 \\
26 & 0.39 \\
27 & 0.40 \\
28 & 0.40 \\
29 & 0.36 \\
30 & 0.27 \\
\hline
\end{tabular}

\subsubsection{Reliability of self-esteem scale}

The researcher used test/retest with a time interval of three-months between the two applications and the reliability of the total score of the scale coefficient reached 0.74 and to ensure the reliability of the scale on the Jordanian environment. Reliability of self-esteem has been measured in its three dimensions by using Cronbach's alpha; table (4) shows the values of reliability coefficients for Family self-esteem, school self-esteem, the Peer self-esteem.

Table 4. Values of reliability coefficients for Family self-esteem, school self-esteem, the Peer self-esteem

\begin{tabular}{ll}
\hline Dimension & Cronbach's alpha constancy coefficient \\
\hline family self-esteem & 0.74 \\
school self-esteem & 0.70 \\
Peer self esteem & 0.47 \\
\hline
\end{tabular}

The data of table indicates an increase in the value of Cronbach Alpha to the dimension of a family of self-esteem as valued at (0.74), as well as the school self-esteem dimension as valued at (0.70) and for the dimension of the Peer self-esteem (group Friends) the value of reliability was relatively weak reaching the value of (0.47) and its' clear from this table that the total score of the scale was (0.64) After applying it to students.

\subsubsection{Scale of emotional intelligence:}

There were many researches and studies aimed to measuring the emotional intelligence, the study conducted by Salovi and colleagues (1995) has revealed that emotional intelligence through the use of mood scale features which measures the degree of interest, which express individuals feelings, and clarity of experience these feelings and beliefs about how to get rid 
of negative moods, or persist in positive moods. The researchers saw that the interest in emotions will help you to identify the individual differences that distinguish individuals who have emotional intelligence who are able to show their feelings to themselves and others.

Tapia study ( Tapia 1998)) aimed to examine the psychometric properties of the list of the emotional Intelligence Inventory, as well as find relationship between emotional intelligence as measured in that list, and intelligence also be measured by Otis Lennon test for School capability, in addition to this emotional intelligence was measured in the light of the scores of verbal and mathematical derivative from the first test of school calendar and the grade average achievement and the following demographic variables: Race and gender, level of education of the parents. Then the results yielded that the scale have a high degree of validity and reliability where the stability of scale reached Cronbach's alpha equation (0.81). In addition to the results indicated that there is no statistically significant relationship between the scores of subjects on Otis Lennon test on the ability of school and their grades on the list of emotional intelligence, which shows the weak relationship between emotional intelligence and general intelligence. There were also a weak relationship between emotional intelligence and academic achievement, while no statistically significant relationship between emotional intelligence and the average achievement scores, And to this side there are no differences in emotional intelligence, according to each of the racial variable, the variable level of parental education, and on the other side, the females got better scores than the males on the emotional intelligence scores. then the researcher ended that the list of emotional intelligence tool have a high degree of validity and reliability makes it unsuitable for use for research purposes in the field of emotional intelligence.

Based on the previously introduced the current researcher chose the emotional intelligence scale which prepared by bar-on in his fifty-eight phrases where he re-legalize it on the Jordanian environment also its validity and reliability has been measured on a sample of (40) students. By using measure the validity of internal consistency of the scale positions through the correlation coefficients between the degree of each phrase and the total phrases scale, so the correlation coefficients ranged between $(0.70$ to 0.85$)$ which is statistically significant coefficients at the level of $(\alpha=0$. 05). In addition to this the reliability of the scale has been measured by using the method of calculating the re-measurement (re-application). The time interval between the first application and the second was two weeks on a sample of 40 students, with a reliability coefficient between the two applications (0.85). These results indicated that the emotional Intelligence Scale have a good Psychometric characteristics.

\section{Results of the Study}

The purpose of this study is to Develop Ryden self-esteem test on Jordanian universities students and to investigate its relationship with Bar-On emotional intelligence test; it also aims to investigate the effect of gender on self-esteem.

To answer the questions of the study; the researcher calculates means and standard deviations and the relative weight of the variables of the study. And the researcher displays in this part 
the answers of questions posed above at the research problem:

The first question: What is the level of emotional intelligence scores among Jordanian university students?

To answer this question; means, standard deviations and relative weight have been measured of each dimension of scale separately; it can be seen in table (5).

Table 5. Means, standard deviations, and the relative weights of emotional intelligence

\begin{tabular}{lllllll}
\hline Emotional intelligence. & $\begin{array}{l}\text { Number } \\
\text { of items }\end{array}$ & $\begin{array}{l}\text { total } \\
\text { degree }\end{array}$ & Means & $\begin{array}{l}\text { standard } \\
\text { deviation }\end{array}$ & $\begin{array}{l}\text { The relative } \\
\text { weight\% }\end{array}$ & Ranking \\
\hline $\begin{array}{l}\text { Emotional intelligence(total } \\
\text { degree) }\end{array}$ & 58 & 290 & 206.7 & 18.1 & 71.3 & \\
$\begin{array}{l}\text { The second dimension of } \\
\text { empathy }\end{array}$ & 55 & 41.2 & 6.4 & 75.0 & 1 \\
$\begin{array}{l}\text { The third dimension to } \\
\text { regulate emotions }\end{array}$ & 65 & 46.7 & 5.4 & 71.9 & 2 \\
$\begin{array}{l}\text { Fifth dimension of social } \\
\text { networking dimension of }\end{array}$ & 45 & 31.9 & 4.6 & 71.0 & 3 \\
$\begin{array}{l}\text { The first dimistration } \\
\text { emotions adminimen }\end{array}$ & 75 & 52.6 & 5.8 & 70.1 & 4 \\
$\begin{array}{l}\text { Fourth Dimension } \\
\text { emotional knowledge }\end{array}$ & 10 & 50 & 34.2 & 4.2 & 68.4 & 5 \\
\hline
\end{tabular}

Relative weight was calculated by dividing the arithmetic mean for each dimension on total degree for each dimension then multiplying by 100 .

As seen from table (5) the mean score of emotional intelligence among Jordanian university students was (206.7) degrees and standard deviation was (18.1) and relative weight was $(71.3 \%)$; which indicates that the level of emotional intelligence among Jordanian university students is high.

As the scale of emotional intelligence has five dimensions it was noted that the second dimension (empathy) ranked first with a mean of (41.2), and a standard deviation of (6.4) and relative weight of (75\%) followed in second place the third dimension (to regulate emotions) the relative weight was $(71.9 \%)$, then ranked third in the fifth dimension (social networking) the relative weight was $(71 \%)$ and ranked fourth in the first dimension (Emotion management) and a relative weight of $(70.1 \%)$ While the first dimension occupied the fifth and last place (knowledge emotional) and the relative weight was (68.4\%). The result can be explained by the special high level of emotional intelligence among Jordanian university students in general by the high proportion of empathy prevailing between the Jordanian university students and their ability to regulate their emotions and social communicate their emotions and their ability to increase their knowledge and emotional management of the basic dimensions of emotional intelligence.

The second question: What is the level of self-esteem scores among Jordanian university students? 
To answer this question and to identify the level of self-esteem among Jordanian university students; the means, standard deviations and relative weight to the point of self-esteem is calculated as shown in Table (6).

Table 6. Means, standard deviations, and relative weights

\begin{tabular}{|c|c|c|c|c|c|}
\hline self-esteem scale & $\begin{array}{l}\text { Number of } \\
\text { items }\end{array}$ & Total degree & Mean & $\begin{array}{l}\text { Standard } \\
\text { deviation }\end{array}$ & $\begin{array}{l}\text { The relative } \\
\text { weight } \%\end{array}$ \\
\hline self-esteem & 30 & 90 & 69.6 & 8.6 & 77.3 \\
\hline
\end{tabular}

Relative weight was calculated by dividing the arithmetic mean for each dimension on total degree for each dimension then multiplying by 100 .

As seen from the above table that the mean of self-esteem among Jordanian university students was (69.6) and a standard deviation of (8.6) and relative weigh of (77.6) and this shows that Jordanian university students have got a high self-esteem, and this result could be interpreted in light of Jordanian university students' vision for themselves and their self-esteem and their achievement.

The third question: To answer this question T-Test was used for two separate samples, The comparison between the means of male grades and the means of female grades in emotional intelligence and its' five dimensions this is illustrated in table (7)

Table 7. The results of the (T) test for comparison between the means of males and females in emotional intelligence

\begin{tabular}{lllllll}
\hline Emotional intelligence & Gender & $\mathrm{N}$ & Mean & $\begin{array}{l}\text { Standard } \\
\text { deviation }\end{array}$ & $\mathrm{t}$ & $\mathrm{Sig}$ \\
\hline Emotions administration & Male & 89 & 53.4 & 5.2 & 2.0 & 0.04 \\
& Female & 121 & 51.8 & 6.2 & & $\mathrm{Sig}$ \\
Empathy & Male & 89 & 42.1 & 6.1 & 1.84 & 0.07 \\
& Female & 121 & 40.5 & 6.3 & & Not Sig \\
Regulate emotions & Male & 89 & 47.5 & 5.2 & 1.86 & 0.06 \\
& Female & 121 & 46.1 & 5.4 & & Not Sig \\
Emotional knowledge & Male & 89 & 34.1 & 4.0 & 0.08 & 0.94 \\
& Female & 121 & 34.1 & 4.4 & & Not Sig \\
Social communication & Male & 89 & 32.4 & 4.6 & \multirow{2}{*}{1.28} & 0.02 \\
& Female & 121 & 31.6 & 4.6 & & Not Sig \\
Emotional intelligence & Male & 89 & 209.5 & 17.7 & 2.15 & 0.03 \\
& female & 121 & 204.2 & 17.9 & & Sig \\
\hline
\end{tabular}

The value of "T"at a freedom level of 107 and Sig level of (0.05) equals 1.96 
As seen in table No. (7) there are statistically significant differences between the means of males' scores and the scores of females' scores in emotional intelligence as it was (2.15) which is greater than the (T) value which is equal to (1.96); suggesting that male students have more emotional intelligence than female students with a mean degree of emotional intelligence of male students (209.5), while the mean scores of female students reached (204.2).

As for the dimensions of the scale it has been found that there are statistically significant differences between mean scores of males and females degrees in the emotions administration dimension where the (t) value reached (2) which is greater than the value of indexed (T) which is equal to (1.96); signifying that male students manage emotions in a positive way more than females, with an average male score of (53.4), while the average female scores were (51.8) and also noted that there were no statistically significant differences between males and females in the following dimensions of emotional intelligence: (empathy, emotion regulation, emotional knowledge, and social communication), Which indicates that the males and females have equal degrees in the following dimensions (empathy, emotion regulation, emotional knowledge, and social communication). This result clarifies the third question where there were not statistically significant differences between male and female students in some dimensions of emotional intelligence of students, namely: empathy, regulating emotions and emotional knowledge, and social communication.

While statistically significant differences were found between male and female students in the emotions administration management and also in the total score of emotional intelligence. this outcome can be interpreted in the light of the student's ability to achieve the accomplishments and his sense of it, where he feels optimistic and expressed it smoothly more than the female student and also male students have a greater opportunity to deal with the attitudes of the public and educational life, and thus their achievements are available through this opportunity, and the culture in the Jordanian society the subject of the study relay on men to take family responsibilities more than females; and therefore students feel their achievements available to the nature of their gender.

The fourth question: Is there a statistically significant effect of emotional intelligence on the self-esteem of students in Jordanian universities?

To answer this question, the researcher used simple linear regression analysis to study the impact of emotional intelligence on self-esteem, as well as to know (the relative importance of emotional intelligence, as shown in table (8)

It is evident from Table (8) that the value of $(t)$ is statistically significant at the level of $(0.01)$; which refers to signify the impact of emotional intelligence on the self-esteem of Jordanian university students, it was found that emotional intelligence has an impact on self-esteem, it was noted that B coefficient is positive, which indicates that the more emotional intelligence rises among students; the more their self-esteem rises, and vice versa, emotional intelligence has a role of about $(0.05 \%)$ of the total variation of the self-esteem; which shows that $(0.05 \%)$ from the change in self-esteem is due to emotional intelligence. 
Table 8. The results of multiple regression analysis to study the effect of emotional intelligence on self-esteem

\begin{tabular}{llcc}
\hline Independent variable & $\begin{array}{l}\text { B } \\
\text { coefficient }\end{array}$ & $\begin{array}{c}T \\
\text { value }\end{array}$ & \\
\hline Fixed limit & 47.6 & 7.3 & $* * 0.01$ \\
Emotional intelligence & 0.10 & 3.4 & $* * 0.01$ \\
Multiple correlation coefficient $^{\mathrm{R} 2}$ & 0.05 & & \\
$\mathrm{~F}(1.217)$ & $* * 11.5$ & & \\
\hline $\mathbf{P}<\mathbf{0 . 0 1}$ & &
\end{tabular}

\section{Conclusion}

It is evident from the above results that the rate of emotional intelligence is high among the Jordanian university students and also that the impact of emotional intelligence is evident in the self-esteem and this is a logical result.

In light of the previous findings the researcher felt that attention should be given to emotional intelligence and its development among the Jordanian university students and to prepare educational programs that will raise the level of intelligence of the students in general, in such programs the dimensions of emotional intelligence especially emotions administration and controlling it should be focused on, and also the empathy dimension showing the high level of these dimensions among the respondents.

The researcher also felt that other studies must be conducted especially in the Jordanian environment to reveal the extent of the relationship between emotional intelligence and other types of intelligence. As well as conducting applied studies; for construction of training programs for Jordanian university students to increase their awareness of their feelings and their ability to manage their emotions as well as providing necessary educational environment to raise their emotional efficiency.

\section{References}

Abi Samka, N. (2000). The relationship between emotional intelligence and academic achievement in eleventh grade Auburn university at Montgomery. Retrieved from http://members.Foruncity.com

Argyle, M. (1967). The Psychology of Interpersonal Behavior. Penguin Books, Harmondsworth, UK .

Bourey, J., \& Miller, A. (2001). Do you know what your emotional IQ is?, The British Journal of Administrative Management, October, 4-10.

Cohen, A. (1959). Some implications of self-esteem for social influence, In C. Hovland and I. [anis (eds), Personality and Persuasibility, Vol. 2. New Haven: Yale University Press, pp. $102-20$. 
Foote, D. (2001). What's your 'Emotional Intelligence? Computer world, 35(7), 28.

Furnham, A. (2006). Trait Emotional Intelligence and Happiness. Social behavior and Personality, 31(8), 815-824. https://doi.org/10.2224/sbp.2003.31.8.815

Goleman, D. (1995). Emotional Intelligence. Why it can matter more than I.Q. New-York: Bantam.

Goleman, D. (1997). Beyond IQ: developing the leadership Competencies of emotional Intelligence, Paper presented of the (2'nd) International Competency Conference, London

Lamanna, M. (2000). The relationships among emotional intelligence, locus of control and depression in selected cohorts of women. Unpublished $\mathrm{PhD}$. thesis, university of temple available: www.lib.unmi.com/dissertations

Lindley, L.D. (2001). Personality, other dispositional variables, and human adaptability. unpublished $\mathrm{PhD}$ thesis, university of lowa state available. Retrieved from www.lib.unmi.com/dissertations

Mayer, J., \& Salovey, P. (1997). What is emotional Intelligence. In Salovey et al, (Ed.), Emotional development and emotional intelligence. Educational implications, New York. Basic Books. Inc, PP 1-34. https://doi.org/10.1080/00223891.1990.9674037

Mayer, J., DiPaolo, M., \& Salovey, P. (1990). Perceiving affective content in ambiguous visual stimuli: A component of emotional intelligence. Journal of Personality Assessment, 54, 772-781.

Moussa, R., \& Hattab, S. (2003). The differences in some psychological variables in light of the variables of emotional intelligence and sexual abuse in al Azhari adolescent. Journal of the Faculty of Education - Ain Shams University, 27(2), 153-191.

Pfeiffier, S. (2001). Emotional intelligence popular and elusive construct. Roeper Review, 23(3), 138-142. https://doi.org/10.1080/02783190109554085

Robbins \& Scott. (2000). Emotional intelligence, translation Safa Asar and Aladdin Kafafi, Cairo, Dar Al Quba for printing, publishing and distribution.

Roberts, R., Zeidner, M., \& Matthews, G. (2001). Does emotional intelligence meet traditional standards for an "intelligence"? Some new data and conclusions. Emotion, 1(3), 196-231. https://doi.org/10.1037/1528-3542.1.3.196

Salovey, P., Mayer, J. D., Goldman, S., Turvey, C, \& Palfai, T. (1995). Emotional attention, Clarity, and repair: Exploring emotional intelligence using the Trait Meta-Mood Scale. In J. W. Pennebaker (Ed.), Emotion, disclosure, and health (pp. 125-154). Washington, D.C.: American Psychological Association. https://doi.org/10.1037/10182-006

Smith, C. (1967). The antecedents of self-esteem. San Francisco: Freeman.

Sorour, S. (2003). Skills of facing pressure and its relation to each of the emotional 
intelligence and control center. Journal of future Education, 29, 9-45

Tapia, M. (1998). A Study of the relationships of the emotional intelligence inventory. Diss. abs. Inter., 59(9A), 3421

\section{Copyright Disclaimer}

Copyright for this article is retained by the author(s), with first publication rights granted to the journal.

This is an open-access article distributed under the terms and conditions of the Creative Commons Attribution license (http://creativecommons.org/licenses/by/3.0/). 